\title{
URBAN VISUAL AIR QUALITY JUDGMENTS: RELIABILITY AND VALIDITY
}

\author{
THOMAS R. STEWART, PAULETTE MIDDLETON AND DANIEL ELY \\ Environmental and Societal Impacts Group, National Center for Atmospheric \\ Research, ${ }^{*}$ Boulder, Colorado 80307, U.S.A.
}

\begin{abstract}
A procedure based on judgments of human observers for measuring visual air quality in urban areas is described, and its reliability and validity are examined using the results of several studies conducted in a metropolitan area. It is concluded that the procedure provides a measure that is sufficiently reliable and valid to warrant its use in studies of the causes and consequences of changes in visual air quality. Substantial agreement was found among individuals with regard to judgments of visual air quality, but the possibility of differences between experienced and inexperienced observers requires further investigation. The paper provides an example of methods that can be used, and issues that should be addressed, in the development of perceived environmental quality indices.
\end{abstract}

\section{Introduction}

The protection of visual air quality (VAQ) is an emerging concern in the evaluation of policies, projects, and other actions that affect air quality. The Clean Air Act, for example, provides for the preservation of visual air quality in pristine areas in the United States of America. In urban areas air quality policy has dealt primarily with the health-related effects of air pollution. Visual air quality, however, is likely to become an important concern, particularly in western U.S. cities which have a tradition of relatively clear air and mountain vistas. Since woodburning for homeheating and sale of diesel automobiles, both of which lead to higher emissions of visibility-reducing pollutants, have been increasing, the likelihood of significant change in visual air quality is growing. Since visual air quality is one of the primary sources of information that people use to evaluate air pollution (Barker, 1976), changes in visual air quality can have significant political implications.

Studies of urban visual air quality that will provide the scientific basis for urban planning or regulation require the development of a sound measure or "perceived environmental quality index' (Craik and Zube, 1976) for VAQ. Daniel (1976) discussed the importance of demonstrating the reliability, validity, and usefulness of such indices. Despite the importance of VAQ, procedures for measuring VAQ in urban areas and for predicting the impact of policies on VAQ have not yet been established.

Visual air quality depends upon the effect of the atmosphere on the visual experience of a person viewing an outdoor scene. It is distinct from other non-visual impacts of air quality, such as health effects or economic effects. A judgment of visual air quality is an aesthetic judgment based on those visually perceived elements of scenes

* The National Center for Atmospheric Research is operated by the University Corporation for Atmospheric Research and is sponsored by the National Science Foundation. 
that are affected by atmospheric conditions. In urban areas, perceptual elements that have an important impact on visual air quality include the color of the air, the clarity with which distant objects can be seen and the presence or absence of a border between clear air and discolored air. Depending on the judgment of an observer, atmospheric conditions may degrade the aesthetic quality of a scene, as when urban haze obscures a mountain backdrop, or enhance it, as when haze or fog adds interest to a landscape.

Since visual air quality is fundamentally a human response to atmospheric phenomena, a measure of VAQ must be based on, or validated against, human responses (Craik, 1983). The importance of the human observer in the measurement of VAQ has been recognized in a number of previous studies of VAQ in pristine areas (Malm et al., 1980, 1981, 1983; Latimer et al., 1981, 1983) and in urban areas (Mumpower et al., 1981; Middleton et al., in press), all of which use judgments as the basic measure of VAQ.

While there is general agreement among researchers investigating VAQ with regard to the need for human observations, there is not agreement about the appropriate procedures for obtaining such observations. The lack of agreement arises because there are a number of issues that must be addressed in the design of a study of visual air quality. For example, should observations be taken at one site or at several sites? Should one obtain a few judgments each from many observers or many judgments per observer from a few observers? How should the observers be instructed or trained? In particular, should they be told to judge VAQ in a specific manner, or should they be allowed to decide for themselves what constitutes good or bad VAQ? These issues, and others important to VAQ research, have been discussed by Middleton et al. (1983).

This report describes a procedure for obtaining judgments of VAQ in urban areas that has been developed at the National Center for Atmospheric Research (NCAR) over the past three years. Results obtained using this procedure in VAQ studies conducted in the Denver metropolitan area are examined with respect to the following two questions.

(1) Reliability. To what extent does the procedure produce similar judgments under identical conditions? In other words, what is the extent of error in VAQ judgments obtained using this procedure?

(2) Validity. Does the procedure measure what it is supposed to measure? If the procedure is to be used in studies addressing the problem of VAQ protection, then it must, indeed, measure VAQ and not something else such as beauty of the urban landscape itself.

\section{Procedure}

We have conducted studies of visual air quality in Denver during summer 1979, winter 1980, summer 1980, winter 1981, and winter 1982. Although relevant results from the last four studies are included in this paper, the procedure described in this section is that used in the latest study. This procedure is a refinement of those used in previous studies which have been described in Mumpower et al. (1981) and Middleton et al. (Note 1; in press). The procedure includes (a) use of paid observers who each make a large number of field observations at several sites during a period of several weeks, (b) training that emphasizes careful recording of observations and adherence to 
predetermined schedule and procedures, but leaves the judgment of what constitutes good or bad visual air quality entirely up to the observer, and (c) a balanced schedule of observations with no systematic pattern of rotation among sites.

\section{Observers}

Observers were recruited through announcements placed on bulletin boards in strategic locations in Denver. After checking applicants' references, 10 people were invited to participate in a one-week training and pilot study with the understanding that only six would be selected for the main study. Eight of the 10 appeared at the training session for the pilot study which was held in mid-December. At the training session, the eight judged the visual air quality of 50 photographic slides (to serve as baseline for comparison with future judgments), and then the observational procedures and forms were explained. In both the pilot study and the main study observers were paid $\$ 6 / \mathrm{h}$ plus a mileage allowance for driving their cars to the observations sites.

In the pilot study, the eight observers made observations and photographed views at five sites in groups of four or more observers during six days. All observers followed a predetermined schedule, and the field manager (an NCAR support scientist) was present at most observations to answer questions about the procedures and to note any problems that occurred. Each of the eight observers who participated in the pilot study made approximately 35 site visits. Their completed forms were checked for errors and each observer's photographs were examined for quality.

The pilot study provided a 'warm up' period, assured that the observers were thoroughly trained in the procedures, made it possible to discover problems in the procedures and correct them before the main study, and provided a record to use in evaluating each potential observer for the main study. The last function of the pilot study is important because the quality of the observer data depends on hiring observers who work carefully and follow directions meticulously.

Two observers who participated in the pilot study were not used during the main January 1982 field study because the budget would support only six observers. The criteria for selection were explicit and involved following the observation schedule, taking pictures correctly and completely filling out the judgment forms (minimizing missing data). One of the observers withdrew herself from consideration by not showing up for scheduled observations the last day and a half of the pilot study. The second observer was not selected because she had serious problems with missing data (she frequently skipped questions) and throughout the pilot study was never able to master the operation of her camera. The decisions about who would and would not participate in the main study were made before the data from the pilot study were analysed and made solely on the basis of the observers' ability to carry out instructions.

The observers in the winter 1982 study were typical of those who participated in previous studies. All observers were highly motivated to participate in the study. Of the six observers, two were female. Observers' ages ranged from 19 to 43 years. They included a photographer, an unemployed Ph.D., three full-time students, and a part-time student who was self-employed as a marketing researcher. Three of the observers had lived over 10 years in the metropolitan area, two observers had been in the area about five years, and the sixth observer had recently moved to the west 
from New York state. The field manager also made observations during the study, making a total of seven observers.

\section{Observations}

Each observer was given a time and location for each site visit during the three week period of the study (11 to 31 January). Upon arriving at the site, observers first recorded their overall impression of VAQ in the metropolitan area (on a scale from 1 - extremely poor to 7 - extremely good) as well as the cloud cover (1-clear, 2 - scattered clouds, 3-broken clouds, 4 - over-cast). Next they made a series of ratings for each of the 3 to 5 prespecified directional views from that site. The ratings included the visual air quality in the specified direction (directional VAQ), how clearly they could see specific target objects (usually buildings or mountains, from 1-very poorly to 7-very clearly), the sharpness of a border between clear air and discolored air (from 1-no border to 7-very sharp, distinct border), and their opinion of the source of any degradation in visual air quality-natural or human (from 1-natural sources to 7-human sources). In addition, the air color was rated in comparison to a selected set of Munsel color chips. After all ratings were made, the observers photographed each prescribed view using Kodachrome 25 film in a $35 \mathrm{~mm}$ single lens reflex camera with a $50 \mathrm{~mm}$ lens.

Since previous studies have shown that data can be lost due to inadvertent errors in recording, a multi-stage error checking system was employed in this study. First, the observer checked his or her own forms each day. Then all observers' forms were checked daily by another observer. The forms were checked again by the field manager on a regular basis. Since the field manager contacted each observer at least every other day, he was able to alert observers to any problems with their forms. Once the data were stored on a computer disk, an extensive error identifying program was used to check times against the schedule, identify out-of-range data, and make other consistency checks to assure that dates, times, sites, and directions were properly recorded. Finally, a manual check of randomly selected records was performed to detect any major sources of error that may not have been found by the program. There were none.

\section{Sites}

Five of the six observers and the field manager made observations at five different sites. The number of sites was reduced to five from the eight of 10 used in previous studies in order to allow more replications among observers. An observation is replicated if two or more observers visit the same site at approximately the same time. Replications are important for assessing reliability and individual differences among observers. The sites (Figure 1) generally provided vistas over the Denver area in several directions, although one downtown site ('C') was included with views in two of the four directions restricted by tall buildings.

The sixth observer made all of his observations from the roof of a greyhound racing track northeast of downtown Denver. This site ('A') was selected as the primary site for the study because of its location (in the high pollution area yet not consistently influenced by major nearby sources). During the study special pollutant monitoring equipment was set up and operated by the Environmental Sciences Research Laboratory of the U.S. Environment Protection Agency at that site. Three observers were scheduled to be at the primary site during each observation period. 


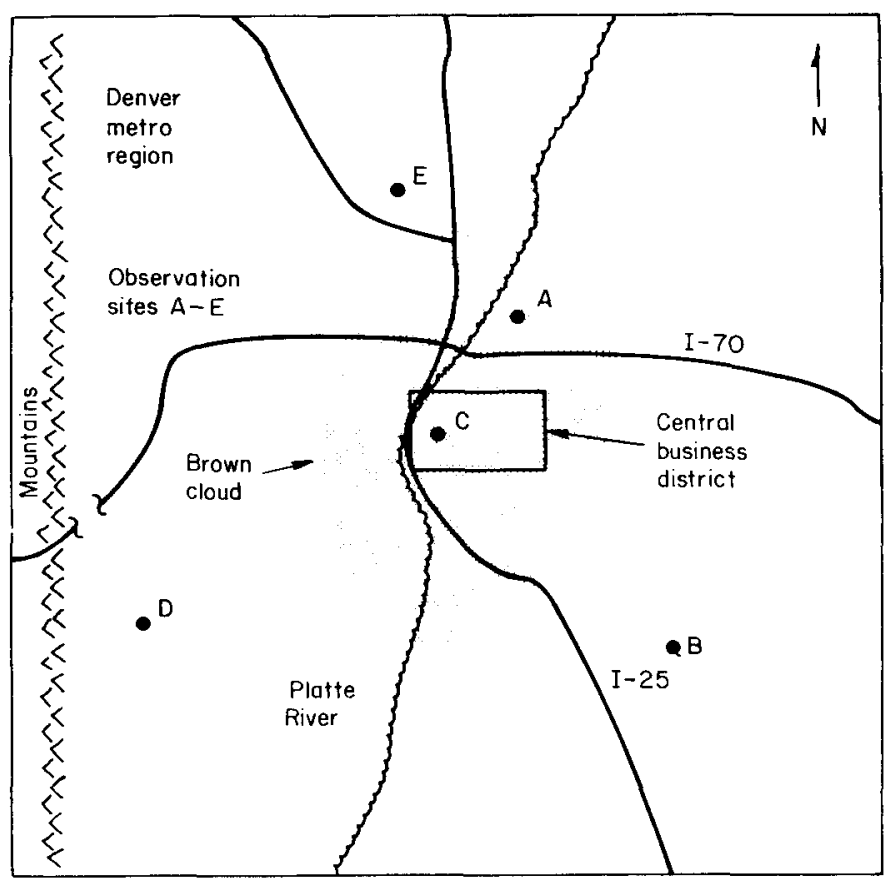

FigurE 1. Schematic showing locations of observation sites.

\section{Schedule}

Three observation periods were defined for each day: 0800-1030 h, 1030-1300 $\mathrm{h}$ and 1330-1600 h. Each observer worked six days per week and worked during two of the three observation periods on a given day. The observers were able to visit three observation sites during each period worked, so each observer could make a maximum of 108 site visits during the period of the study. The actual number of completed site visits for the six observers and the field manager was 727 . Scheduling site visits was a difficult task requiring: (a) approximately equal number of visits by each observer to each site during the study (with the exception of the observer stationed at the primary site); (b) approximately equal number of morning, midday, and afternoon visits to each site; (c) approximatley equal number of visits to each site on each day; (d) approximately equal number of replications between each pair of observers; and (e) no systematic pattern of rotation among sites for any observer. In other words, the schedule balanced several important factors while not imposing systematic routines on the observers that might bias their judgments.

\section{Ratings of photographs}

In addition to making field observations, the observers rated a number of photo- 
graphs. A standard slide projector and white screen was used and a small incandescent bulb illuminated the observers' rating forms and color chips. The ratings made following the conclusion of the field study included ratings of a set of 50 photographs selected from all those made during the field study and a second set of 50 selected from the observer's own photographs. In each case the sample of photographs selected was stratified so that the distribution of VAQ for the photographs approximated the distribution of VAQ judgments over the field judgments.

The results of the studies which indicate the reliability and validity of VAQ judgments are described below.

\section{Reliability}

Reliability has to do with the 'repeatability' of judgments (Nunnally, 1978). A perfectly reliable judge always makes the same judgment on two different occasions if conditions are identical. Reliability decreases as error in the judgments increases. Direct assessment of reliability is not possible in field studies because each observation is made under unique conditions. It is possible, however, to estimate a lower bound for reliability. If the errors of measurement of two measures are independent, then the expected value of the correlation between them cannot exceed the product of the square roots of their reliabilities (see, for example, Guilford, 1954, p. 400). Sample values of the correlation between two variables will exceed the product of the square roots of their reliabilities only by chance, and the probability of this occurring decreases as sample size increases. Correlations that indicate the degree of reliability of VAQ judgments are described in this section.

\section{Replicated observations}

Independent judgments of VAQ that can be used to estimate a lower bound for reliability are provided by the replicated observations. A high correlation between judgments made independently by different observers at the same time and site indicates both that the observers are highly reliable and that they agree. A low correlation between observers indicates either (a) low reliability for at least one of the observers, or (b) individual differences between reliable judgments, or (c) both unreliability and individual differences. Assessment of reliability and individual differences are therefore closely linked.

Since differences among observers with regard to both perception and judgment are common, it would not be surprising to find differences with regard to VAQ judgments. Differences might result from different ways of using the visual information (e.g. attention to different parts of the scene), different experiences or information gained prior to the observation (e.g. a radio report of high pollution) or different criteria for visual air quality.

Agreement among observers is measured by the Pearson product moment correlation coefficient. This measure is used because it is invariant with respect to differences in the mean or standard deviation of judgments. The 1-7 scale of visual air quality is at best an interval scale of measurement, with no meaningful zero point or objective anchors, and differences in the means and standard deviations likely reflect biases in the way that people use rating scales (e.g. avoidance of the end points of the scales) rather than important differences in how visual air quality is judged. The question addressed then is not whether different people assigned identical ratings 
to the same view, but rather the extent to which their ratings co-vary across views and times.

The design of the winter 1982 study included a number of replicated observationsobservations by two or three observers at the same site within a few minutes of one another. Sixty-one per cent of the replicated observations were within $10 \mathrm{~min}$ of each other and the median time separation was seven minutes. Eighty-two per cent were within $20 \mathrm{~min}$ and only 10 per cent were separated by more than $30 \mathrm{~min}$. Therefore, the paired observations were generally made under nearly identical atmospheric conditions.

The number of replicated site visits for each pair of observers varies from 17 to 49. Based on the number of common site visits per pair, the $7 \times 7$ matrix of betweenobserver correlations was computed. For overall visual air quality, the correlations range from 0.70 to 0.90 with a median of 0.81 . For directional air quality, the correlations range from 0.72 to 0.87 with a median of 0.82 . If we assume that all observers are approximately equally reliable, then we can infer from these correlations that there is substantial similarity in observers' judgments of VAQ and that the reliability of the typical observer is almost certainly above 0.70 and probably nearer to $0 \cdot 80$.

\section{Judgments of photographs}

Another indication of the reliability of visual air quality judgments comes from photographic studics. The use of photographs as visual material for VAQ judgments ensures that each observer has identical information for judgment. After completing their field judgments, observers in the summer 1980, winter 1981 and winter 1982 studies judged VAQ for a set of 50 color photographs. For the seven observers (six paid observers and the field manager) in the winter 1982 study, the correlation between the judgments of pairs of observers varied from 0.58 to 0.88 with a median of 0.75 . Slightly lower correlations were obtained with photographs for seven observers who participated in the summer 1980 and winter 1981 studies (minimum, 0.47; maximum, 0.81 ; median, $0.67)$ but these still indicate substantial reliability and agreement. These results for an urban area are consistent with the findings of studies conducted in pristine areas (Latimer et al., 1981, 1983; Malm et al., 1981).

Another correlation that can be used to estimate a lower bound for reliability is the correlation between an observer's judgments of VAQ during the field study and his or her later judgments of photographs of the same views. These correlations were obtained for observers in the winter 1981 and 1982 studies. The medians were 0.79 and $0 \cdot 76$, respectively, confirming the high reliability of the observers' field judgments.

\section{Respondents}

The results reported above indicate that the VAQ judgments of experienced observers are reliable and in agreement. This section compares the judgments of experienced observers with those of inexperienced citizens.

In studies conducted in the winter of 1980 , summer of 1980 , and winter of 1981 , observers were instructed to interview two passersby, called 'respondents', at each site after they made their own observations. Correlations were computed over observations between each observer's VAQ judgments and the corresponding judgments from his or her respondents. Only the judgments of the first respondent for each observation were used because it was often not possible to obtain a second 
respondent within a short period of time. Use of only the first respondents' judgments therefore maximizes both the sample size and the similarity of atmospheric conditions judged by observer and respondent.

The correlation betwen an observer's judgments and those of the respondents that he or she interviewed is a measure of the similarity between an experienced observer and a group of inexperienced citizens. For the three studies combined, 14 observers obtained an overall VAQ judgment from respondents for at least 10 observations. The 14 observer-respondent correlations ranged from 0.20 to 0.82 with a median of $0 \cdot 48$. The sample sizes ranged from 22 to 103 . Fifteen observers obtained directional VAQ judgments from respondents following at least 10 observations. The 15 observerrespondent correlations ranged from 0.33 to 0.84 with a median of 0.50 . The sample sizes ranged from 33 to 125 .

The correlations between observers and their respondents are lower and vary more among observers than do the observer- observer correlations. There are three possible explanations for the lower correlations.

(a) Individual differences in means and standard deviations among respondents may depress the correlations. Since each respondent judged only one view, each observer-respondent correlation is a correlation between $n$ judgments by a single observer paired with judgments of the same views made by $n$ different respondents. It may be assumed that if the respondents had the opportunity to make a series of judgments, individual differences among respondents' means and standard deviations would be found, just as such individual differences were found among observers. Differences in means and standard deviations may reflect differing biases in the use of rating scales and different reference points or 'anchors' for good or bad VAQ. Such individual differences do not affect observer-observer correlations but will tend to depress observer-respondent correlations.

(b) The respondents' judgments may be less reliable than the observers. An indication of the low reliability of the respondent's judgments is the low correlations between the judgments of the first and second respondents when two respondents were interviewed. For the summer of 1980 , the correlation between the overall VAQ judgments of the 373 pairs of respondents interviewed was 0.26 . In the winter of 1981 the correlation for 136 pairs of respondents was 0.41. For directional VAQ, the correlation between the first and second respondent was 0.45 in the summer of $1980(n=166)$ and 0.39 in the winter of $1981(n=75)$. The number of pairs of respondents is lower for directional than for overall VAQ because each respondent judged only one view and that was not always the same view judged by the other respondent.

(c) There may be systematic differences between observers and respondents, perhaps introduced by the observers' training and experience in judging VAQ or by the different roles assumed by observers and citizens (Craik, 1983). In order to examine the possibility that systematic differences between observers, as a group, and respondents, as a group, were masked by the relatively low reliability of respondents, the daily average VAQ judgments for the two groups were compared for two studies. Over the 35 days of the summer 1980 study, the correlation between the average overall VAQ for observers and the daily average overall VAQ for respondents was $0 \cdot 73$. The corresponding correlation for directional visual air quality judgments was 0.82 . For 26 days of the winter 1981 study, observer and respondent daily averages correlated 0.87 for overall VAQ and 0.77 for directional VAQ. While these correlations 
between average ratings of groups of judges do not rule out the possibility of substantial differences between particular observers and respondents, they do indicate similarity in group averages. Thus there do not appear to be substantial systematic differences between observers and respondents.

\section{Summary}

Both the correlations among observers and the correlations between judgments made in the field and from photographs indicate high reliability of VAQ judgments for trained observers. These results also indicate considerable agreement among judgments of VAQ made by different observers. The results suggest that judgments of untrained respondents are less reliable than judgments of trained observers. This may be because the untrained respondents are more susceptible than trained observers to errors introduced by inattention, misunderstanding of instructions, or the influence of irrelevant cues.

It should be noted that the reliability of VAQ measurement can be increased by the use of more than one observer. Since the observers' judgments are highly correlated, the means of several observers' judgments would be even more reliable than the individual observers' judgments (see Guilford, 1954, p. 393). For example, using the general form of the Spearman-Brown prophecy (Nunnally, 1978, p. 211), it is estimated that if the VAQ judgments of three observers have intercorrelations of 0.8 , then the mean of those judgments would have a reliability of 0.92 . If 0.4 is taken as an estimate of respondent reliability (based on the correlations between respondents reported above) then it would require a group of 17 untrained respondents to achieve the same reliability as a group of three trained observers.

\section{Validity}

The results presented in the previous sections indicate that judgments of visual air quality can be made reliably and that the judgments of different observers are similar. Although these are desirable qualities for a measure of VAQ, they do not establish its validity.

To paraphrase Guilford (1954, p. 398), validity has to do with what judgments, in this case VAQ judgments, really measure and what they will predict. The validity of a measure is dependent upon its intended use; a measure that is valid for one use may not be valid for another. In this report, we are interested in the validity of VAQ judgments for policy-relevant studies of visual air quality.

A traditional test of validity is based on prediction of a 'criterion'. For example, an aptitude test which is intended to predict school achievement is validated by correlating test scores with the criterion of actual school achievement (grades) for a sample of students. In the case of VAQ, however, no practical criterion for validation exists because there is no independent measure of 'true' VAQ that could be compared with VAQ judgments.

It is tempting to accept the validity of the judgments obtained by our procedure simply because people were instructed to judge visual air quality (rather than, say, scenic beauty), they indicated that they understood the instructions, they were located at a vantage point where visual information about air quality was available, and they were observed looking at the scene. Such acceptance would amount to defining visual air quality operationally as the response of an observer on a visual air quality scale. 
A sceptic would rightly ask for evidence that the observers' responses correspond to the concept of visual air quality that is important to the public and its representatives. The skeptic is asking for evidence of 'construct' validity. Visual air quality is a 'psychological construct', i.e. it is abstract and not directly observable. The validity of any procedure which purports to measure such a construct cannot be taken for granted.

Construct validity requires that the measure behave as one would expect a valid measure to behave (Nunnally, 1978, p. 103). Construct validity is assessed by evaluating relations between the measure and other variables in the light of theory and common sense (Cronbach and Meehl, 1955). Construct validity is demonstrated by the presence of relations with variables that are related to the construct and by the absence of relations with variables that are not related to the construct. Construct validation is, by its nature, an open-ended process, i.e. no amount of evidence for construct validity is sufficient to prove validity, because there is always the possibility that some new evidence can be found which will create serious doubt about the validity of the measure.

In the case of VAQ the "theory" that is the basis for construct validation is a set of qualitative, common-sense statements that could hardly be disputed; that is, that visual air quality is based on visual information, that visual air quality is related to clarity of objects, color of the air, presence of a border, sun angle, windspeed, and aerosol properties (e.g. concentrations, light scattering) and that VAQ should not be strongly determined by the specific non-air-quality-related characteristics of particular views. These statements suggest necessary, although not sufficient, conditions for the validity of a measure of VAQ.

Evidence about the validity of the field observation procedure for measuring VAQ is drawn from the relation between VAQ field judgments and (a) another measure of the same construct-VAQ judgments of photographs, (b) measures that may elaborate the construct-judged clarity, color, and border, and (c) measures of related but different constructs sun angle, windspeed, aerosol light scattering, and views. In the following sections the evidence that the VAQ measure behaves as a valid measure should behave is summarized.

\section{Relations between judgments of photographs and field observations}

The high correlations between photographic and field observations reported above as evidence for the reliability of VAQ judgments also provide evidence of their validity. These correlations indicate that VAQ judgments are, in fact, based on visual elements of the particular view. If the VAQ judgments had been strongly influenced by nonvisual cues such as smell or impressions of pollution gained from media reports earlier in the day, then they could not correlate highly with later judgments based on photographs which do not include these cues.

\section{Correlation between $V A Q$ and other judgments}

As described above, observers judged not only VAQ, but also the clarity of certain target objects, the color of the air, and the presence or absence of a border between clear air and discolored air. A valid measure of VAQ should be positively related to the clarity of target objects (the more clearly the target can be seen, the better the $\mathrm{VAQ}$ ), negatively related to air color (the more that the air color departs from 
TABLE 1

Correlations among field judgments $(n=1348)$

\begin{tabular}{lcccc}
\hline & $\begin{array}{c}\text { Visual } \\
\text { air } \\
\text { quality }\end{array}$ & $\begin{array}{c}\text { Clarity of } \\
\text { objects in } \\
\text { distance }\end{array}$ & $\begin{array}{c}\text { Color } \\
\text { of } \\
\text { air }\end{array}$ & $\begin{array}{c}\text { Sharpness } \\
\text { of } \\
\text { border }\end{array}$ \\
$\begin{array}{c}\text { Visual air } \\
\text { quality }\end{array}$ & 1.0 & & & \\
$\begin{array}{c}\text { Clarity of objects } \\
\text { in distance }\end{array}$ & 0.87 & 1.0 & & \\
$\begin{array}{l}\text { Color of air } \\
\begin{array}{l}\text { Sharpness of } \\
\text { border }\end{array}\end{array}$ & -0.62 & -0.47 & 1.0 & 1.0 \\
\hline
\end{tabular}

a clear or colorless condition, the lower the VAQ), and negatively related to the sharpness of a border between clear and discolored air (the sharper border corresponds to lower VAQ). The correlations among averaged observer judgments of directional VAQ, target clarity, color and border for 1348 directional judgments in the winter 1982 study are presented in Table 1 . The pattern of correlations is similar to that obtained in previous studies.

The correlations between directional VAQ and clarity, color, and border are significant and in the expected direction. Since all four judgments were made at the same time by the same observers, there is the possibility that the correlations are created by a 'halo' effect. Similar patterns of correlations are obtained, however, between VAQ judgments of observers in the field and clarity, color, and border judgments made after the field study from the photographs taken during the field observations.

A multiple regression analysis was performed using VAQ as the dependent variable and clarity, color and border judgments as the independent variables. The multiple correlation was 0.90 and the regression weights for standardized scores (beta weights) for clarity, color, and border were $0 \cdot 74,-0 \cdot 20$, and -0.09 , respectively. All beta weights were statistically significant beyond the 0.01 level. The high multiple correlation indicates that clarity, color, and border account for most of the reliable variation in visual air quality.

\section{Relation between $V A Q$ and sun angle}

Since the angle between the sun and observer has a strong effect on the scattering and absorption of light by suspended particles in the air (Chandrasekhar, 1960), sun angle should have an effect on VAQ. This effect should be most pronounced for morning and evening observations when the sun may be directly behind the observer or in front of the observer, depending upon the direction. One would expect a strong relation between direction of view and VAQ in the morning, and an opposite relation in the late afternoon. Figure 2 shows that this relation holds. The interaction between time of day and direction of view exhibited in the figure is statistically significant $(F=4.84 ;$ df. $=2,471 ; P<0.01)$.

\section{Relation between $V A Q$ and windspeed}

Strong breezes are associated with low pollution levels in Denver (Haagenson, 1979), 


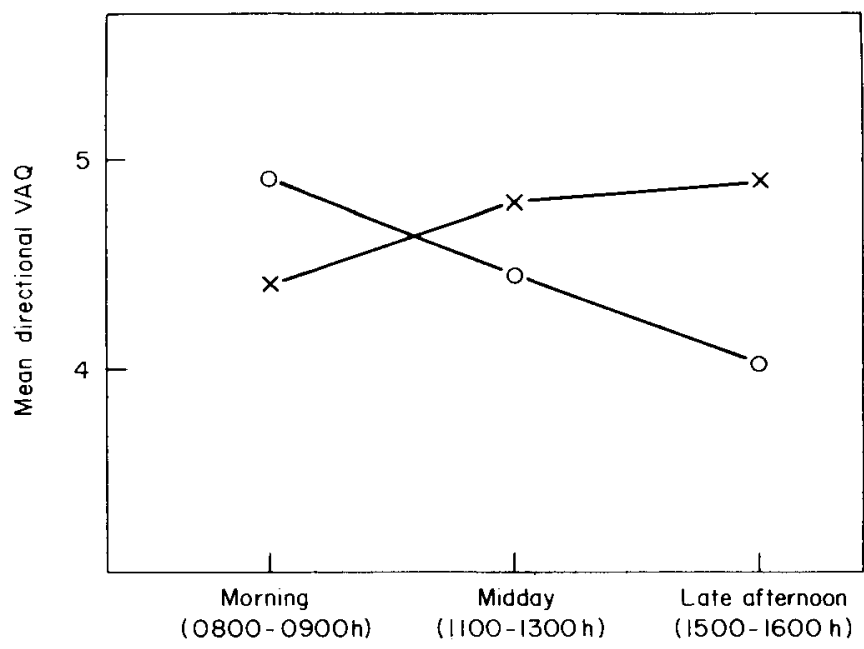

Time of day

FIgURE 2. Mean directional visual air quality by direction of view and time of day. $\mathrm{X}=$ North-east, east, south-east views; $\mathrm{O}=$ north-west, west, south-west views.

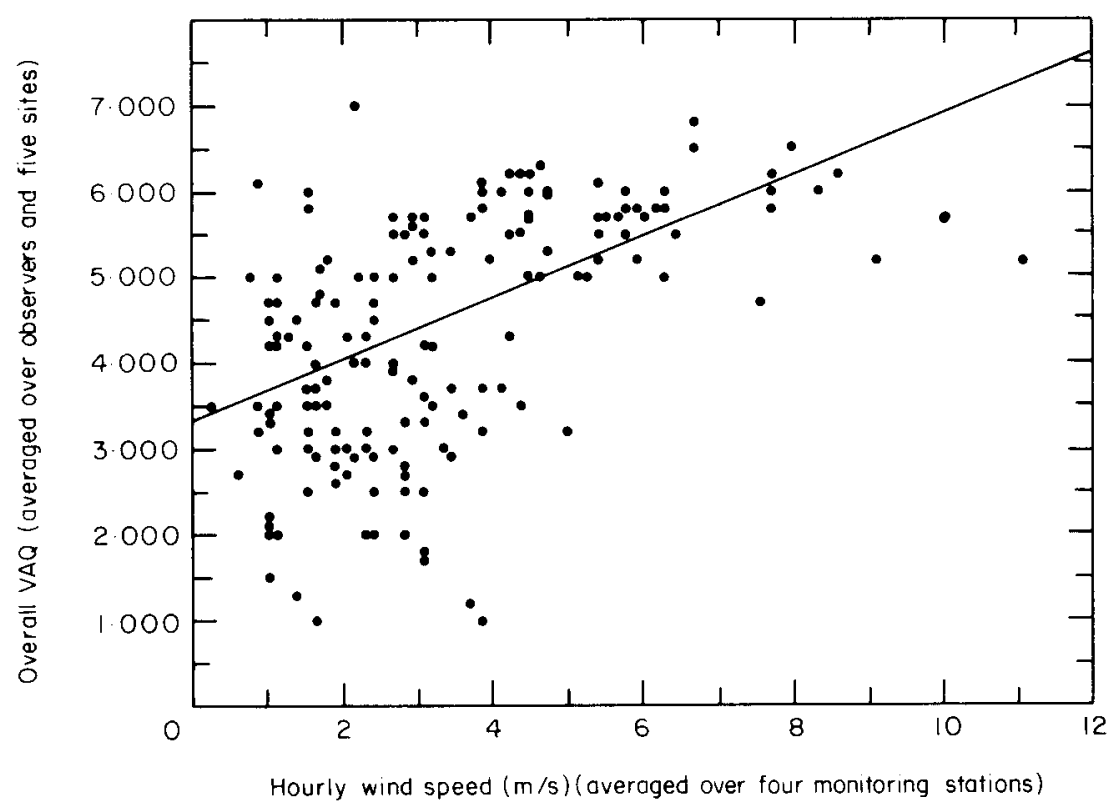

FIGURE 3. Relation between average overall VAQ and average windspeed for the winter 1982 study. Where $n=169 ; r=0.557$ and $y=0 \cdot 38 x+3.08$.

and therefore should also be associated with good visual air quality. The scatterplot in Figure 3 shows the relation between windspeed, averaged over four existing measuring stations for each hour of the winter 1982 study, and visual air quality, averaged over observers and sites at the same hours. The plot clearly shows that the higher windspeed corresponds to better VAQ, while at lower windspeeds, VAQ depends 
on other factors. The slight lowering of VAQ at high windspeeds that is exhibited in the figure is possibly due to blowing dust.

\section{Relation between $V A Q$ and light scattering}

Perhaps the most important relation for establishing the validity of a measure of VAQ is its relation with aerosol properties, in particular aerosol light scattering, since small aerosols (suspensions of solid or liquid particles in the air that are less than $2.5 \mu \mathrm{m}$ diameter), not gases (except for nitrogen dioxide), interact strongly with sunlight in the visual wavelength range (van de Hulst, 1957; Wolff et al., Note 2). These small aerosols contribute much more to the Denver haze problem than does nitrogen dioxide or large aerosols (Heisler et al., Note 3; Waggoner and Weiss, Note 4). A VAQ measure that was not sensitive to aerosol properties would have little credibility and would be of little use in policy making, since it is difficult to imagine how visual air quality could be improved if not by reducing the pollution related to the problem.

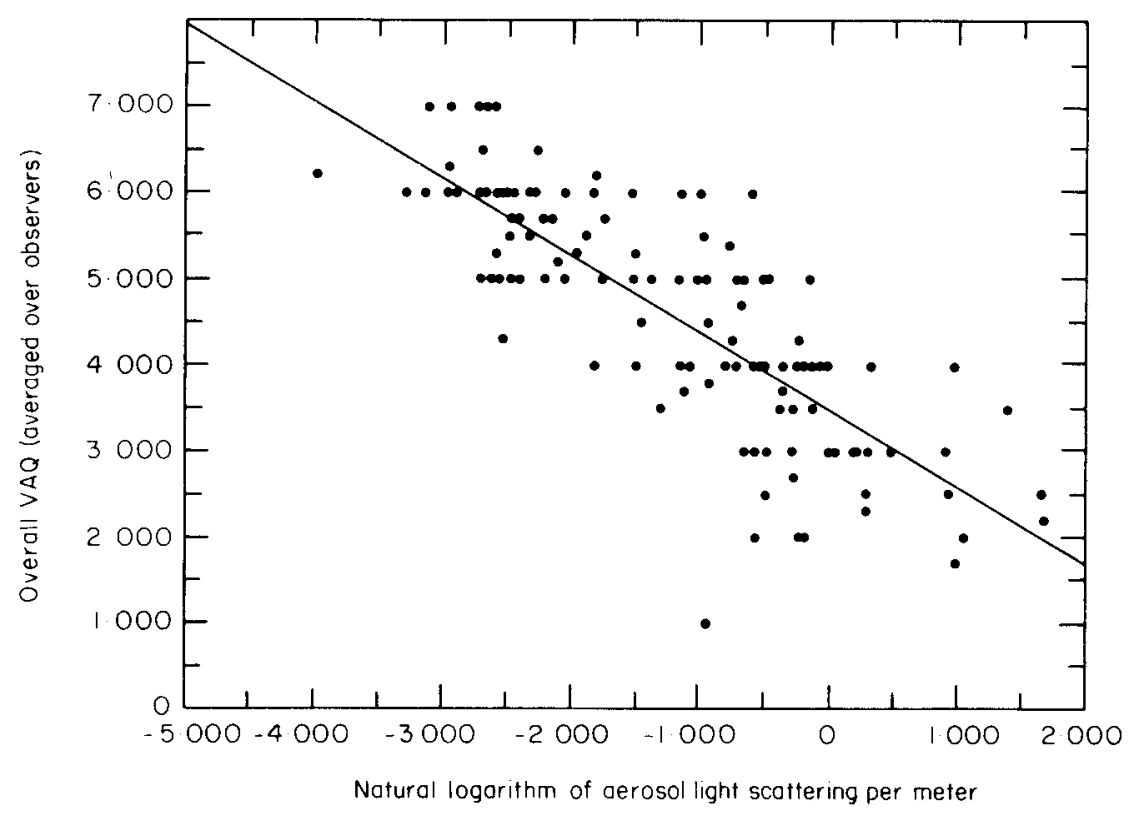

FIGURE 4. Relation between average overall VAQ and aerosol light scattering at the primary site for the winter 1982 study. Where $n=121 ; r=-0 \cdot 802 ; y=-0 \cdot 9 x+3 \cdot 47$.

Figure 4 is a scatterplot showing the relation between overall VAQ judgments, averaged over observers at the primary site, and aerosol light scattering measurements made by a heated nephelometer (Model \#1591, Meteorology Research, Inc.) provided and operated at that site by the Environmental Science Research Laboratory of the Environmental Protection Agency. The correlation is $-0 \cdot 80$, indicating that the relation is strong and in the expected direction. A perfect relation is not expected because (a) aerosol light scattering is not the same construct as VAQ and (b) the instrument measured aerosol light scattering at only one location and at ground level, 
while the overall VAQ judgments were largely affected by above-ground concentrations in the observer's line of sight.

Figure 4 also indicates that VAQ judgments are sensitive to changes in physical properties of the atmosphere. Throughout the range of aerosol light scattering observed in the winter 1982 study, there is a close relation between changes in aerosol light scattering and changes in VAQ judgments.

\section{Relation between $V A Q$ and views}

Since VAQ affects the quality of the scene being viewed, it is expected that the scene itself will have some effect on VAQ judgments (Malm et al., 1981; Latimer et al., 1981). However, if there is little variance in judgments of a particular view, relative to the variation across different views, then the judgments probably reflect scenic quality rather than visual air quality. If, on the other hand, there is substantial variation in judgments of a specific view, this fact, along with evidence for validity cited above, suggests that much of the variation in judgments can be attributed to changes in visual air quality.

To estimate the variation explained by differences among views as a percentage of total variation, the $\eta^{2}$ statistic was used (Blalock, 1979). The $\eta^{2}$ statistic is analogous to a squared correlation coefficient between views and VAQ. The $\eta^{2}$ was 0.08 , indicating that only $8 \%$ of the total variation in directional VAQ can be attributed to different views. Therefore, the judgments are strongly influenced by something other than specific characteristics of views.

\section{Summary}

These results do not definitely establish the construct validity of the measure, but they increase confidence in its validity for policy-relevant studies of VAQ. As noted above, it is tempting to accept the validity of VAQ judgments simply because VAQ is what people were asked to judge and, by definition, no person is more qualified than any other to judge VAQ (given normal vision). The human mind, however, remains a "black box' which does not always respond to instructions or use information in predictable ways. Because this is the case, the exercise of establishing construct validity becomes necessary.

\section{Conclusion}

The results of five studies involving over 2250 observation site visits by 25 trained observers and 1956 interviews of passersby indicate that our procedure can provide a useful measure of VAQ. Field-based judgments can be used to monitor VAQ, and to investigate the relation between VAQ and other variables, such as pollutant concentrations and, ultimately, pollutant sources. Further, VAQ judgments can be used as a basis for validating other instruments or techniques for measuring VAQ.

The procedure could also be used to examine the relation between VAQ and other policy-relevant variables. For example, does VAQ on a given day influence one's psychological sense of well-being or 'quality of life"? Does VAQ have an effect on awareness of air pollution, concern about air pollution, or willingness to act to reduce pollution? Does VAQ affect the attractiveness of a city to investors, business, or new employees?

A basic technical component of the procedure is the selection and training of 
observers to insure that instructions are meticulously followed. Further research is required to determine whether this process limits the generality of the obtained measure of VAQ. In particular, we do not know whether any person can be trained to make reliable VAQ judgments and whether observers so trained differ in some important way from the general population. However, the results comparing trained observers and untrained respondents obtained so far are encouraging in this regard. They indicate that although judgments of trained observers are more reliable than judgments of untrained citizens, the reliable components of their judgments are similar.

Two factors that may limit the generality of the results should be mentioned. First, all five studies were conducted in the Denver area. Although the procedure should perform equally well in other cities, further research will be required to demonstrate its generality. A second factor is the cause of variability in aerosol concentrations during the studies. Although pollution-causing emissions vary diurnally and weekends differ slightly from weekdays, the major cause of variation in aerosol concentrations during these studies was variation in meteorological conditions which affects the aerosol chemistry and dispersion. Policy makers are concerned with changes in VAQ due to changes in emissions from, for example, automobiles, or power plants. Although we can think of no reason that the reliability or validity of VAQ judgments should change depending on the alternative causes of variation in aerosol concentrations, we cannot rule out the possibility. Correlations are affected by the distributions of the variables (Blalock, 1979) and different causes of variation may well produce different distributions. As a result correlations based on emission changes over time may differ from those based on meteorological effects with emissions held relatively constant. Since it is not possible to vary emissions systematically, we cannot assess the importance of this effect.

The procedure used in these studies to obtain judgments of VAQ is a promising technique for measuring urban visual air quality. The studies show that a carefully designed and executed field observation procedure can provide a valid and reliable measure of VAQ.

\section{Acknowledgements}

The authors appreciate helpful comments by Richard Anthes, Tony Delany, Robin Dennis, Charles Judd, Rob Hamm, Richard Katz, Maria Krenz, Steven Rhodes, two reviewers and the co-editor of this journal on an earlier version of this paper.

The authors wish to acknowledge the support of both Region VIII and the Environmental Science Research Laboratory of the U.S. Environmental Protection Agency during the research described in this article.

Although the research described in this article has been funded in part by the U.S. Environmental Protection Agency through interagency agreement number AD-49-F-0-167-0 to the National Science Foundation, it has not been subjected to Agency review and therefore does not necessarily reflect the views of the Agency and no official endorsement should be inferred. C. W. Lewis of the Environmental Sciences Research Laboratory supplied the nephelometer measurements reported in Figure 4.

The research described here was facilitated by the Center for Research on Judgment and Policy, Institute on Behavioral Science, University of Colorado. The project was 
supported in part by BRSG Grant \#RR07013-14 awarded by the Biomedical Research Support program, Division of Research Resources, National Institutes of Health.

\section{Reference Notes}

1. Middleton, P., Stewart, T. R. and Dennis, R.L. (1981). Urban visual air quality study: Interim report to Region 8 EPA. Environmental and Societal Impacts Group, National Center for Atmospheric Research, Boulder: NCAR.

2. Wolff, G. T., Countess, R. J., Groblicki, P. J., Ferman, M. A., Cadle, S. H. and Muhlbaier, J. L. (1980). Visibility-reducing species in the Denver 'Brown Cloud', Part II. Sources and temporal patterns. General Motors Research Publication GMR-3394, Env. No. 80.

3. Heisler, S. L., Henry, R. C., Watson, J. G. and Hidy, G. M. (1980). The 1978 Denver Winter Haze Study, Vol. II, Document No. P-5417-1, prepared for Motor Vehicle Manufacturers' Association of the United States Inc.

4. Waggoner, A. P. and Weiss, R. E. (1980): The Color of Denver Haze. In 73rd Annual Meeting of the Air Pollution Control Association, Paper 80-58.5.

\section{References}

Barker, M. L. (1976). Planning for environmental indices: observer appraisals of air quality. In K. H. Craik and Zube, E. H. (eds), Perceiving Environmental Quality: Research and Applications, New York: Plenum.

Blalock, H. M. (1979). Social Statistics (revised second edition). New York: McGraw-Hill.

Chandrasekhar, S. (1960). Radiative Transfer. New York: Dover.

Craik, K. H. (1983). A role theoretic analysis of scenic quality judgments. In R. D. Rowe and L. G. Chestnut (eds), Managing Air Quality and Scenic Resources at National Parks and Wilderness Areas. Boulder: Westview Press.

Craik, K. H. and Zube, E. H. (1976). The development of perceived environmental quality induces. In K. H. Craik and E. H. Zube (eds), Perceiving Environmental Quality: Research and Applications. New York: Plenum.

Cronbach, L. J. and Meehl, P. E. (1955). Construct validity in psychological tests. Psychological Bulletin, 52, 281-302.

Daniel, T. C. (1976). Criteria for development and application of perceived environmental quality indices. In K. H. Craik and E. H. Zube (eds), Perceiving Environmental Quality: Research and Applications. New York: Plenum.

Guilford, J. P. (1954). Psychometric Methods. New York: McGraw-Hill.

Haagenson, P. L. (1979). Meteorological and climatological factors affecting Denver air quality. Atmospheric Environment, 13, 79-85.

Latimer, D. A., Hogo, H. and Daniel, T. C. (1981). The effects of atmospheric optical conditions of perceived scenic beauty. Atmospheric Environment, 15, 1865-74.

Latimer, D. A., Hogo, H., Hern, D. H. and Daniel, T. C. (1983). Effects of visual range on the beauty of national parks and wilderness area vistas. In R. D. Rowe and L. G. Chestnut (eds), Managing Air Quality and Scenic Resources at National Parks and Wilderness Areas. Boulder: Westview Press.

Malm, W. C., Leiker, K. K. and Molenar, J. V. (1980). Human perception of visual air quality. Journal of Air Pollution Control Association, 30(2), 122-31.

Malm, W., Kelley, K., Molenar, J. and Daniel, T. C. (1981). Human perception of visual air quality (uniform haze). Atmospheric Environment, 15, 1875-90.

Malm, W., MacFarland, K. K., Molenar, J. and Daniel, T. (1983). Human perception of visual air quality (layered haze). In R. D. Rowe and L. G. Chestnut (eds), Managing Air Quality and Scenic Resources at National Parks and Wilderness Areas. Boulder: Westview Press.

Middleton, P., Stewart, T. R., Dennis, R. D. and Ely, D. (1983). Implications of NCAR's visual air quality assessment method for pristine areas. In R. D. Rowe and L. G. Chestnut (eds), Managing Air Quality and Scenic Resources at National Parks and Wilderness Areas. Boulder: Westview Press. 
Middleton, P., Stewart, T. R. and Dennis, R. L. (in press). Modeling human judgments of visual air quality. Atmospheric Environment.

Mumpower, J., Middleton, P., Dennis, R. L., Stewart, T. R. and Viers, V. (1981). Visual air quality assessment: Denver case study. Atmospheric Environment, 15, 2433-41.

Nunnally, J. C. (1978). Psychometric Theory (2nd edit.). New York: McGraw-Hill. van de Hulst, H. C. (1957). Light Scattering by Small Particles. Wiley: New York.

Manuscript received: 5 March 1983

Revised manuscript received: 6 June 1983 